EGU21-12910

https://doi.org/10.5194/egusphere-egu21-12910

EGU General Assembly 2021

(c) Author(s) 2021. This work is distributed under

the Creative Commons Attribution 4.0 License.

\title{
Geochemical evidence of a floating Arctic ice sheet and underlying freshwater in the Arctic Mediterranean in glacial periods
}

\author{
Walter Geibert ${ }^{1}$, Jens Matthiessen ${ }^{1}$, Ingrid Stimac ${ }^{1}$, Jutta Wollenburg ${ }^{1}$, and Ruediger Stein ${ }^{1,2,3}$ \\ ${ }^{1}$ Alfred Wegener Institute Helmholtz Centre for Polar and Marine Research, Marine Geochemistry, Bremerhaven, Germany \\ (walter.geibert@awi.de) \\ ${ }^{2}$ MARUM - Center for Marine Environmental Sciences, University of Bremen, Bremen, Germany \\ ${ }^{3}$ Faculty of Geosciences, University of Bremen, Bremen, Germany
}

Numerous studies have addressed the possible existence of large floating ice sheets in the glacial Arctic Ocean from theoretical, modelling, or seafloor morphology perspectives. Here, we add evidence from the sediment record that support the existence of such freshwater ice caps in certain intervals, and we discuss their implications for possible non-linear and rapid behaviour of such a system in the high latitudes.

We present sedimentary activities of ${ }^{230} \mathrm{Th}$ together with ${ }^{234} \mathrm{U} /{ }^{238} \mathrm{U}$ ratios, the concentrations of manganese, sulphur and calcium in the context of lithological information and records of microfossils and their isotope composition. New analyses (PS51/038, PS72/396) and a re-analysis of existing marine sediment records (PS1533, PS1235, PS2185, PS2200, amongst others) in view of the naturally occurring radionuclide ${ }^{230} \mathrm{Th}_{\mathrm{ex}}$ and, where available, ${ }^{10} \mathrm{Be}$ from the Arctic Ocean and the Nordic Seas reveal the widespread occurrence of intervals with a specific geochemical signature. The pattern of these parameters in a pan-Arctic view can best be explained when assuming the repeated presence of freshwater in frozen and liquid form across large parts of the Arctic Ocean and the Nordic Seas.

Based on the sedimentary evidence and known environmental constraints at the time, we develop a glacial scenario that explains how these ice sheets, together with eustatic sea-level changes, may have affected the past oceanography of the Arctic Ocean in a fundamental way that must have led to a drastic and non-linear response to external forcing.

This concept offers a possibility to explain and to some extent reconcile contrasting age models for the Late Pleistocene in the Arctic Ocean. Our view, if adopted, offers a coherent dating approach across the Arctic Ocean and the Nordic Seas, linked to events outside the Arctic. 